\title{
Gender, Division of Unpaid Family Work and Psychological Distress in Dual-Earner Families
}

\author{
Wenting Tao ${ }^{1}$, Bonnie L. Janzen ${ }^{1, *}$, and Sylvia Abonyi ${ }^{1,2}$ \\ ${ }^{I}$ Department of Community Health \& Epidemiology, College of Medicine, University of Saskatchewan, Saskatoon, \\ Saskatchewan, Canada \\ ${ }^{2}$ Saskatchewan Population Health and Evaluation Research Unit, University of Saskatchewan, Saskatoon, \\ Saskatchewan, Canada
}

\begin{abstract}
:
Introduction: Epidemiological studies have only recently begun to address the consequences of unpaid family work (ie., housework and child rearing) for mental health. Although research is suggestive of an association between the division of unpaid family work and psychological health, especially for women, additional research is required to clarify the conditions under which such a relationship holds. The purpose of the present study was to examine more nuanced relationships between the division of family work and psychological distress by disaggregating the family work construct according to type (housework/child rearing), control over scheduling, and evaluations of fairness.

Methods: Analysis of data obtained from a cross-sectional telephone survey conducted in a Canadian city. Analyses were based on 293 employed parents (182 mothers and 111 fathers), with at least one preschool child, living in dual-earner households. Several multiple linear regression models were estimated with psychological distress as the outcome, adjusting for confounders.

Results: For mothers, more perceived time spent in child rearing (particularly primary child care) and high-schedulecontrol housework tasks (e.g. yard work) relative to one's partner, were associated with greater distress. For fathers, perceived unfairness in the division of housework and child rearing were associated with greater distress.

Conclusion: Although methodological limitations temper firm conclusions, these results suggest that the gendered nature of household work has implications for the psychological well-being of both mothers and fathers of preschool children in dual-earner households. However, more longitudinal research and the development of theoretically-informed measures of family work are needed to advance the field.
\end{abstract}

Keywords: Gender, mental health, housekeeping, parenthood, mothers, fathers.

\section{INTRODUCTION}

The study of occupational exposures and their health effects has been an important focus within epidemiology. Although the early emphasis of this research was on men, understanding of the qualities and characteristics of paid work which impact women's health has increased greatly over the last two decades [1], though gaps remain [2,3]. In contrast to paid work, relatively little is known about the characteristics of unpaid family work (ie., housework, child rearing) which may influence well-being [4]. This lack of research attention is likely the result of numerous factors, ranging from bias on the part of researchers in considering household labor as "real work" and therefore worthy of study as a potential determinant of health, to the many conceptual and measurement difficulties in attempting to accurately characterize such a complex, often invisible role [5]. While it is true that

"Address correspondence to this author at the Department of Community Health \& Epidemiology, College of Medicine, University of Saskatchewan, Health Sciences Building, 107 Wiggins Road, Saskatoon, Saskatchewan, S7N 5E5, Canada. Tel: 306-966-7841; Fax: 306-966-7920;

E-mail: bonnie.janzen@usask.ca considerable progress has been made in documenting the gendered allocation of unpaid family work in Canada and elsewhere over the last several decades [6,7], few studies in comparison have studied the potential repercussions of family work for mental health. This is an important gap in the research literature, given the thousands of hours that Canadians in general and women in particular will spend in housework and child rearing over a life time.

Theorizing as to why or how unpaid family work may be related to mental health is quite underdeveloped in the research literature, particularly if compared to the voluminous literature on paid work. Nonetheless, several explanations have been put forth which conceptually link the performance of family work with psychological well-being [8]. Household work has been depicted as a low-prestige activity that is also physically demanding, routine, and isolating. According to this view, because family work involves engaging in many intrinsically unlikeable activities, more time spent in such activities will lead to lower levels of psychological wellbeing. A second explanation linking family work with mental health is the notion of role strain or overload $[8,9]$. Role overload is based on the premise that human energy is lim- 
ited, and the more demands within a role, or the more roles a person occupies, the more strain experienced and the greater the likelihood of negative effects on health and well-being. Thus, more time spent in housework and child rearing may create role overload, particularly if combined with paid work, resulting in time pressure and subsequent psychological strain. The third explanation focuses on the proportion of family work done relative to one's partner, rather than the absolute amount of housework done $[8,10]$. According to equity theory, couples evaluate both what they put into a relationship and what they get out of a relationship; equity between partners is attained when both contribute and benefit fairly within the relationship [11]. The division of family work is one area that can contribute to couples' perceptions of equity or inequity in a relationship, and thus potentially impact psychological well-being. Thus, there are several ways in which the performance of household work could be reasonably associated with mental health outcomes.

However, the limited research which has examined the relationship between exposure to household work and wellbeing has produced conflicting findings. For example, for women, studies have found greater absolute time spent in family work to be associated with poorer mental health, [1214] better mental health, but only up to a particular threshold of hours [15], and unrelated to mental health [8,16,17]. Similarly, several studies have reported that the more proportionate time women spend in household labor relative to their partner, the greater their depression or psychological distress $[15,17,18]$, whereas others have reported no such relationship [12,19-21]. Although men are less often included as participants in studies of family labour and well-being $[18,19,22]$, men's mental health, on average, is less likely to be associated with the division of family work $[8,16,21]$, though exceptions have been noted [12].

Disparate research findings are likely the result of numerous factors. The study participants used in research examining the relationship between family work and mental well-being have varied widely in terms of stage in the family life course, employment status, and family role occupancy. Family and paid work responsibilities and resources vary considerably throughout the adult life course in ways which may impact both the division of family work and its potential impact on health [23]. The parenting of young children is typically among the most challenging phases in a parent's life, particularly when both partners are employed outside the home [24,25]. Although some evidence suggests that younger generations of parents are more likely to share family work more equitably than previous cohorts [26], recent research suggests that many young parents with young children still resort to the traditional division of labour in which mothers do more family work than fathers and fathers do more paid work [24,27,28].

Lack of specificity in the measures used to evaluate exposure to family work may also contribute to the inconsistent findings when examining links between household labor and health outcomes. As commented on by Glass and Fujimoto [12], "when actual or proportionate measures of work hours (paid or domestic) are used to predict depressive symptomatology without considering whether those hours are spent in drudgery or satisfying work, interpretive problems ensue"(p.
181). Thus, like paid work, spending time in certain family work tasks may be a qualitatively different experience than spending time in others. Goldberg and Perry-Jenkins [19] claim that understanding of the relationship between family work and mental health has been impeded by the tendency of researchers to only include measures of housework [12,21] or to combine questions on child rearing and housework into one measure, so that the independent associations of each with mental health, if present, cannot be determined $[15,18,29]$. The few studies which have considered child rearing and housework separately suggest that an unequal division of child rearing may be more strongly associated with women's psychological distress than an unequal division of housework [20,22,30], though exceptions have been reported [16,19].

Family work activities also vary in terms of schedule control, that is, one's "ability to schedule tasks to reflect one's personal needs rather than having to perform the tasks on a schedule independent of one's personal needs" [21 p. 2]. Low-schedule-control tasks, such as laundry and cooking, are those which must typically be done every day and at certain times, with the worker experiencing very little discretion in the scheduling of tasks. In contrast, high-schedulecontrol tasks, such as yard work and car maintenance, are often initiated and completed according to the worker's preference and can often be performed without any time urgency. The performance of high- and low-schedule-control activities is highly gendered within households, with women typically spending more hours on low-schedule-control tasks and men on high-schedule-control tasks [5,7]. Control over work activities has been identified as an important resource for promoting health and well-being in the job stress literature [30,31], and some evidence suggests its importance in family work as well [8,21]. For example, in one study of dual earner couples, for both husbands and wives, more time spent performing low-schedule-control tasks was associated with greater distress, whereas the amount of time spent on high-schedule-control tasks was unrelated to mental health outcomes [21]. Although it is often assumed in the literature that it is the routine, low-schedule control housework activities that are most harmful to well-being [5], little research, with a few exceptions [8,21], has systematically tested this hypothesis.

In addition to distinguishing between the type (housework versus child rearing) and nature (high- versus lowschedule-control) of family work performed when considering mental health outcomes, whether one perceives the division of family work as fair or unfair may also be relevant. Research suggests that, on average, the more time spent in family work relative to one's partner, the more likely it is that the division of household labor will be perceived as unfair [16]. However, performing a disproportionate amount of the family work does not invariably result in perceptions of unfairness. Although a large body of research has been devoted in trying to understand why many women believe the distribution of family work is fair even when performing a larger share [5], relatively few studies have focused on the potential mental health consequences of perceived unfairness in household work. The limited research which does exist suggests a positive association between perceived unfairness in the division of family work and depressive symptoms for 
women, but not for men $[8,12,16]$ However, an important limitation of these studies is the lack of differentiation between housework and child rearing activities, with the exception of Voydanoff [16], who found that perceived unfairness in the division of child rearing and housework independently predicted women's psychological distress, but was unrelated to men's distress.

Although the research to date is suggestive of an association between the performance of family work and psychological distress, especially for women, additional research is required to clarify the conditions under which such a relationship holds. To this end, the purpose of the present study was to explore more nuanced relationships between the division of family work and psychological distress by disaggregating the family work construct according to type (housework versus child rearing), control over the scheduling of housework tasks, and evaluations of fairness (both housework and childrearing). More specifically, using data from a recent survey of parents in dual-earner households involved in the early stages of child-rearing, the following research questions were addressed: 1) Is the division of child rearing and the division of housework differentially associated with psychological distress? 2) Is the division of low-schedulecontrol housework tasks and the division of high-schedulecontrol housework tasks differentially associated with psychological distress? and 3) Is perceived fairness in the division of housework (child rearing) more strongly associated with psychological distress than is the division of housework (child rearing)? Of particular interest when addressing each research question was whether the nature of the relationship between housework, child rearing, and psychological distress differed for mothers and fathers.

\section{MATERIALS AND METHODOLOGY}

\section{Sample and Procedure}

Data for this study originates from a 2005 cross-sectional telephone survey conducted in a mid-size Canadian city. Eligibility requirements were being: 1) English-speaking, 2) between 25 and 50 years of age, 3) employed, and 4) the parent of one or more children under the age of 20 years currently living in the household. In addition to these criteria, our intent was to include a sociodemographically diverse sample of employed parents; to achieve this goal, a data collection grid was applied to ensure that approximately equal proportions of participants were selected for the final sample in regards to gender, age category (25-34 yrs; $35-50 \mathrm{yrs}$ ), and educational attainment (high school or less; some postsecondary; university/college degree). Trained interviewers randomly dialed the phone numbers; in households with more than one eligible person, one person was randomly selected to participate. A computer-assisted telephone interviewing system was used to conduct the interviews. The study was approved by the University's Behavioural Research Ethics Board.

Of the 5300 eligible people contacted, 1160 agreed to participate in the study, resulting in a response rate of $22 \%$. Women comprised $58 \%$ of the sample and half of the participants were less than 35 years of age. The proportion of respondents was evenly distributed between the three educational categories. To explore the potential for sampling bias, we compared the distribution of our respondents' answers with those from the Canadian Community Health Survey, Cycle 3.1 (CCHS) on like questions [32]. The response rate of the CCHS was $78.9 \%$. Although the CCHS is a Canadawide survey, our analysis focused on CCHS respondents living in a similar geographical region as our study participants, who were employed, of similar age, and who were the parent of at least one child living in the household. As expected, compared to respondents from the CCHS 3.1, our sample was significantly younger and had lower educational attainment. Although our sample experienced higher levels of psychological distress, no statistically significant differences emerged according to gender, hours spent in paid work, self-assessed health, or in the proportion with one or more chronic health problems.

To address the goals of this study, participants were restricted to those men and women who were partnered, in a dual-earner household, and the parent of at least one preschool child living in the household. Thus, for the present analysis, the sample size was 293 (182 women and 111 men).

\section{Dependent Variable}

Non-specific psychological distress was assessed by the Kessler-6, a self-report measure requiring respondents to estimate on a 5-point response scale $(0=$ none of the time to $4=$ all of the time) how often in the previous month they had experienced various behavioral, emotional, and cognitive symptoms of psychological distress [33]. The measure is comprised of 6 questions, such as "How often in the past 30 days did you feel that everything was an effort?", "How often did you feel worthless?", and "How often did you feel restless or fidgety?" Respondents' scores were totaled across all the items with higher scores indicating higher levels of psychological distress. Cronbach's alpha for this scale was 0.81 . The K6 has been used extensively in general population samples with strong evidence of validity and reliability reported and it has been shown to be a sensitive screen for DSM-IV disorders [34,35].

\section{Independent Variables}

Four different proportionate measures were constructed to assess the household division of family work [19]. For each of 13 household tasks, participants were asked to indicate, on a 5-point interval scale, how much of the work they typically perform compared to their partner: $1=$ very little/ none; $2=$ some; $3=$ about half; $4=$ most; and $5=$ all. There were five child rearing tasks (e.g., playing with children, travel for children) and eight housework tasks (e.g., washing dishes, paying bills). Responses to the items were summed to form two measures: 1) perceived relative time spent in child rearing, and 2) perceived relative time spent in housework. For each measure, the higher the score, the greater the perceived contribution made relative to one's partner. Scores could range from 8 to 40 for the housework measure and 5 to 25 for the child rearing measure.

Based on the work of Barnett and Shen [21], housework tasks were further divided into high schedule control tasks (e.g., doing outdoor tasks, paying bills, and maintaining vehicles) and low schedule control tasks (e.g., preparing meals, washing dishes, cleaning house, shopping, and washing and 
Table 1. Correlations Among Continuous Study Variables

\begin{tabular}{|c|c|c|c|c|c|c|c|c|}
\hline Variables & & 1 & 2 & 3 & 4 & 5 & 6 & 7 \\
\hline 1 & Age & & & & & & & \\
\hline 3 & Number of children & $* * .55$ & -.08 & & & & & \\
\hline 4 & Psychological demands & .07 & $* * .24$ & .08 & & & & \\
\hline 6 & Perceived relative time in housework & .03 & $*_{-.15}$ & .03 & -.02 & -.06 & & \\
\hline 7 & Perceived relative time in child rearing & -.09 & -.05 & -.01 & .09 & .00 & $* * .39$ & \\
\hline 8 & Psychological distress & .07 & .02 & .03 & .10 & $*_{-.15}$ & .10 & $* * .16$ \\
\hline
\end{tabular}

*p $\leq 0.05 ; * * \mathrm{p} \leq 0.01$

ironing). Thus, two additional measures were constructed: 1) perceived relative time spent in high-schedule-control tasks, and 2) perceived relative time spent in low-schedule-control tasks. For each measure, the higher the score, the greater the perceived contribution made relative to one's partner. Scores could range from 3 to 15 for the high schedule control measure and 5 to 25 for the low schedule control measure.

The measures of perceived fairness were based on two questions that asked respondents to indicate how fair they considered the current division of housework and child rearing to be (1=very unfair to me, $2=$ somewhat unfair to me, $3=$ fair to both, 4 =somewhat unfair to partner, 5 = very unfair to partner) [12]. Participant responses were collapsed into three categories: 1) unfair to me, 2) fair to both, and 3) unfair to partner. Dummy variables were developed to separately represent perceived fairness of child rearing and perceived fairness of housework.

Several variables were included as covariates. Participants' age, number of children, and weekly work hours were treated as continuous variables. Educational attainment was a categorical variable with three groupings: high school or less, some post-secondary, and college/university graduate. Perceived income adequacy was assessed with a single statement ("We have enough money to cover basic needs for food, housing and clothing"), with which participants were asked to indicate their agreement on a scale from one (strongly disagree) to four (strongly agree). The distribution of responses was highly skewed leading to the decision to regroup the variable to form two income adequacy categories: adequate (agree, strongly agree) and inadequate (disagree, strongly disagree). Psychosocial work quality, based on Karasek's job strain model [30], was assessed by two scales: job demands comprised of 9 items (e.g. "My job requires working very fast") and decision latitude, comprised of 8 items (e.g. "I have a lot to say about what happens on my job"). Items for each work quality measure were summed, with higher scores indicating greater job demands/decision latitude. Cronbach's alpha was .73 for decision latitude and .65 for job demands.

\section{Data Analysis}

Pearson product moment correlations were conducted to examine the general pattern of relations among the continu- ous variables. Bivariate analyses were conducted to examine the demographic, social and mental health profile of study participants by gender. Differences between men and women were tested using chi-square tests for categorical variables and t-tests for continuous measures.

To address the three research questions, several multiple linear regression models were estimated with psychological distress as the outcome, adjusting for key covariates. The child rearing and housework variables were entered in separate regression equations to better understand their independent associations with women's psychological distress [19]. Analyses were also conducted separately for mothers and fathers to facilitate the identification of gender-specific associations. For each regression analysis, the covariates were entered first into the model as a block (ie., age, number of children, educational attainment, perceived income adequacy, work hours, job demands, job decision latitude), followed by the primary independent variables, which varied according to the research question. To address research questions 1 and 3 , the independent variables were entered as follows:

Model 1: covariates; Model 2: perceived relative time in housework (child rearing); Model 3: perceived fairness of housework (child rearing). For research question 2, the modeling process was: Model 1: covariates; Model 2: perceived relative time in high-schedule-control housework tasks, perceived relative time in low-schedule-control housework tasks. The effect of adding a block of variables to the regression models was tested at each step by the change in $\mathrm{R}^{2}$.

\section{RESULTS}

Correlations among the continuous variables, displayed in Table 1, are generally low, indicating in relation to each other these measures were adequately orthogonal. The distribution of all study variables, by gender, are shown in Table 2. Men reported spending significantly more hours in paid work compared to women and women reported spending significantly more time than men on housework and child rearing tasks relative to their partner. When the nature of the housework task was considered, men reported significantly more time in high-schedule-control activities and women in low-schedule-control activities. A significantly higher proportion of women than men reported the perceived fairness 
Table 2. Sociodemographic Characteristics and Work (Paid and Unpaid) Variables, by Gender

\begin{tabular}{|c|c|c|}
\hline & Men & Women \\
\hline & \multicolumn{2}{|c|}{ Mean (SD) } \\
\hline Age* & 31.19 ( 4.07) & $32.44(4.66)$ \\
\hline Number of children & $1.59(0.81)$ & $1.71(0.81)$ \\
\hline Weekly work hours** & $42.22(12.36)$ & $36.86(10.36)$ \\
\hline Decision latitude at work* & $25.89(4.85)$ & $27.11(4.63)$ \\
\hline Job demands & $24.49(4.12)$ & $24.28(4.12)$ \\
\hline Perceived relative time in housework $* *$ & $24.77(4.66)$ & $27.75(4.49)$ \\
\hline Perceived relative time in child rearing $* *$ & $15.72(2.48)$ & $16.73(2.80)$ \\
\hline Perceived relative time in low schedule control housework tasks $* *$ & $13.79(4.51)$ & $19.19(3.05)$ \\
\hline Perceived relative time in high schedule control housework tasks** & $10.97(2.51)$ & $8.55(2.69)$ \\
\hline \multirow[t]{2}{*}{ Psychological distress } & $3.96(3.12)$ & $4.00(3.61)$ \\
\hline & \multicolumn{2}{|c|}{ Number (percent) } \\
\hline \multicolumn{3}{|l|}{ Educational Attainment* } \\
\hline High school or less & $44(39.60)$ & $45(29.03)$ \\
\hline Some post-secondary & $25(22.50)$ & $45(29.03)$ \\
\hline College/university & $42(37.80)$ & $65(41.94)$ \\
\hline \multicolumn{3}{|l|}{ Perceived income adequacy } \\
\hline Adequate & $90(81.81)$ & $156(89.14)$ \\
\hline Inadequate & $20(18.18)$ & $19(10.86)$ \\
\hline \multicolumn{3}{|l|}{ Perceived fairness of housework $* *$} \\
\hline Fair to both & $49(44.14)$ & $98(53.85)$ \\
\hline Unfair to partner & $51(45.95)$ & $32(17.58)$ \\
\hline Unfair to me & $11(9.91)$ & $52(28.57)$ \\
\hline \multicolumn{3}{|l|}{ Perceived fairness of child rearing } \\
\hline Fair to both & $76(68.45)$ & $125(68.68)$ \\
\hline Unfair to partner & $14(12.61)$ & $13(7.14)$ \\
\hline Unfair to me & $21(18.91)$ & $44(24.18)$ \\
\hline
\end{tabular}

$* p \leq 0.05 * * p \leq 0.01$

of the division of housework as "unfair to me". Conversely, a significantly greater percentage of men than women reported that the current division of housework as "unfair to my partner". Although women were older and reported a significantly higher level of decision latitude and educational attainment than men, no statistically significant gender differences emerged in regard to perceived income adequacy, number of children, perceived fairness of child rearing tasks, job demands, or psychological distress.

Tables 3 through 5 show the results of the regression analyses, reported separately for men and women, investigat- ing associations between the family work variables and psychological distress, adjusting for key covariates. To improve concordance with the statistical assumptions of linear regression, the dependent variable, psychological distress, was square root transformed and one independent variable, perceived relative time in child rearing, was log-transformed. Inspection of the variance inflation factors and tolerance levels for each regression analysis indicated that multicollinearity was not a major concern.

Table 3 displays the results of the regression analyses for the housework variables and psychological distress. After 
Table 3. Standardized (Beta) Coefficients for OLS Regression of Psychological Distress on Relative Time in Housework and Perceived Fairness of the Division of Housework, by Gender

\begin{tabular}{|c|c|c|c|c|c|c|c|}
\hline \multirow[b]{2}{*}{ Step } & \multirow[b]{2}{*}{ Variable } & \multicolumn{3}{|c|}{ Men } & \multicolumn{3}{|c|}{ Women } \\
\hline & & $\begin{array}{c}\text { Model } \\
1\end{array}$ & $\begin{array}{c}\text { Model } \\
2\end{array}$ & $\begin{array}{c}\text { Model } \\
\mathbf{3}\end{array}$ & $\begin{array}{c}\text { Model } \\
1\end{array}$ & $\begin{array}{c}\text { Model } \\
2\end{array}$ & $\begin{array}{c}\text { Model } \\
3\end{array}$ \\
\hline \multirow[t]{9}{*}{1} & Age & .07 & .06 & .04 & .03 & .05 & .06 \\
\hline & Number of children & -.18 & -.17 & -.10 & -.00 & -.03 & -.05 \\
\hline & Educational attainment ${ }^{\mathrm{a}}$ & & & & & & \\
\hline & Some post-secondary & -.04 & -.05 & -.10 & .12 & .11 & .13 \\
\hline & High school or less & .02 & .02 & -.13 & .02 & .00 & .01 \\
\hline & Inadequate income ${ }^{b}$ & .19 & .19 & $* * .28$ & $* * .21$ & $* .19$ & **.21 \\
\hline & Weekly work hours & -.04 & -.04 & -.07 & -.06 & -.06 & -.05 \\
\hline & Job demands & -.09 & -.09 & -.15 & $* .18$ & $* .18$ & $* .19$ \\
\hline & Decision latitude at work & $*_{-.21}$ & $*_{-.21}$ & -.19 & -.04 & -.03 & -.02 \\
\hline 2 & Perceived relative time in housework $\mathrm{k}^{\mathrm{c}}$ & & .03 & .02 & & .13 & .14 \\
\hline \multirow[t]{5}{*}{3} & Perceived fairness (housework) & & & & & & \\
\hline & Unfair to me & & & $* * .38$ & & & -.03 \\
\hline & Unfair to partner & & & .14 & & & -.10 \\
\hline & Adjusted $\mathrm{R}^{2}$ & 0.05 & 0.04 & 0.13 & 0.06 & 0.07 & 0.06 \\
\hline & $F(d f)$ for change in $R^{2}$ & $\begin{array}{c}1.65 \\
(8,95)\end{array}$ & $\begin{array}{c}0.07 \\
(1,94)\end{array}$ & $\begin{array}{r}* * 6.04 \\
\quad(2,92)\end{array}$ & $\begin{array}{l}* 2.26 \\
(8,163)\end{array}$ & $\begin{array}{c}2.97 \\
(1,162)\end{array}$ & $\begin{array}{c}0.75 \\
(2,160)\end{array}$ \\
\hline
\end{tabular}

a compared to university/college graduates; ${ }^{\mathrm{b}}$ compared to adequate income; ${ }^{\mathrm{c}}$ compared to fair to both $* \mathrm{p} \leq 0.05 * * \mathrm{p} \leq 0.01$

taking into account potential confounding variables in Model 1 , the addition in Model 2 of perceived time spent in housework relative to one's partner did not significantly contribute to explaining the dependent variable for men.

$\left(\mathrm{F}_{1,94}=0.07, \mathrm{p}>0.05\right)$ or for women $\left(\mathrm{F}_{1,162}=2.97, \mathrm{p}>\right.$ $0.05)$. The addition of perceived fairness of housework in Model 3 accounted for a statistically significant amount of the variance in psychological distress, above and beyond that explained in Model 2, for men $\left(\mathrm{F}_{2,92}=6.04, \mathrm{p} \leq 0.01\right)$ but not for women $\left(\mathrm{F}_{2,160}=0.75, \mathrm{p}>.05\right)$. Thus, compared to men who perceived the division of housework as fair to both partners, men who perceived the division as unfair to themselves reported significantly higher levels of psychological distress.

The next set of analyses disaggregated the housework variable further, examining whether the division of lowschedule-control tasks and high-schedule-control tasks were differentially associated with psychological distress (Table 4). For men the addition of perceived relative time spent in low-schedule-control tasks and high-schedule-control tasks in Model 2 did not statistically significantly add to explaining the dependent variable, either individually or as a block, after adjustment for the covariates in Model $1\left(\mathrm{~F}_{2,93}=0.14, \mathrm{p}\right.$
$>.05)$. For women, the block addition of perceived relative time spent in high-schedule-control and low-schedulecontrol housework tasks did statistically contribute to the prediction of psychological distress $\left(\mathrm{F}_{2,161}=4.00, \mathrm{p} \leq 0.05\right)$. Greater perceived time spent in high-schedule-control housework tasks relative to one's partner was associated with increased psychological distress among women.

The third set of regression analyses examined relationships between the child rearing variables and psychological distress (Table 5). After taking into account potential confounding variables in Model 1, perceived relative time spent in child rearing added in Model 2 made a statistical significant contribution to explaining psychological distress for women $\left(\mathrm{F}_{1,162}=6.50, \mathrm{p} \leq 0.01\right)$ but not for men $\left(\mathrm{F}_{1,94}=0.90\right.$, $\mathrm{p}>0.05)$. Thus, for women, the more perceived time spent in child rearing relative to one's partner, the greater the psychological distress. The addition of perceived fairness of child rearing in Model 3 contributed significantly to explaining psychological distress for men $\left(\mathrm{F}_{2,92}=4.53, \mathrm{p} \leq 0.01\right)$ but not women $\left(\mathrm{F}_{2,160}=1.42 ; \mathrm{p}>0.05\right)$. Men who perceived the division of child rearing as unfair to themselves had significantly higher psychological distress scores than men who perceived the division as fair to both partners. 
Table 4. OLS Regression of Psychological Distress on Relative Time in Low-Schedule-Control and High-Schedule-Control Housework Tasks, by Gender

\begin{tabular}{|c|c|c|c|c|c|c|}
\hline & \multicolumn{3}{|c|}{ Men } & \multicolumn{3}{|c|}{ Women } \\
\hline & $\mathbf{B}^{\mathrm{a}}$ & $\mathbf{S E}^{\mathrm{a}}$ & $\boldsymbol{\beta}^{\mathrm{a}}$ & $\mathbf{B}^{\mathrm{a}}$ & $\mathbf{S E}^{\mathrm{a}}$ & $\boldsymbol{\beta}^{\mathrm{a}}$ \\
\hline Perceived relative time in low-schedule-control tasks & .00 & .01 & .01 & -.01 & .01 & -.03 \\
\hline Perceived relative time in high-schedule-control tasks & .01 & .02 & .06 & .05 & .02 & $* * .22$ \\
\hline
\end{tabular}

adjusted for age, number of children, educational attainment, income adequacy, weekly work hours, job demands, job decision latitude $* * \mathrm{p} \leq 0.01$

Table 5. Standardized (Beta) Coefficients for OLS Regression of Psychological Distress on Relative Time in Child Rearing and Perceived Fairness of the Division of Child Rearing, by Gender

\begin{tabular}{|c|c|c|c|c|c|c|c|}
\hline Step & Variable & \multicolumn{3}{|c|}{ Men } & \multicolumn{3}{|c|}{ Women } \\
\hline \multirow[t]{6}{*}{1} & Age & .07 & .07 & .05 & .03 & .08 & .07 \\
\hline & Number of children & -.18 & -.19 & -.15 & -.00 & -.02 & -.01 \\
\hline & Some post-secondary & -.04 & -.06 & -.16 & .12 & .11 & .09 \\
\hline & High school or less & .02 & .02 & -.09 & .02 & .03 & .05 \\
\hline & Inadequate income $^{\mathrm{b}}$ & .19 & .18 & $* .24$ & $* * .21$ & $* * .20$ & $* .20$ \\
\hline & Weekly work hours & -.04 & -.04 & -.02 & -.06 & -.01 & -.06 \\
\hline 2 & Perceived relative time in child rearing ${ }^{\mathrm{c}}$ & & .09 & .10 & & $* * .19$ & $* * .22$ \\
\hline \multirow[t]{5}{*}{3} & Perceived fairness (child rearing) & & & & & & \\
\hline & Unfair to me & & & $* * .30$ & & & -.01 \\
\hline & Unfair to partner & & & .19 & & & .13 \\
\hline & Adjusted $\mathrm{R}^{2}$ & 0.05 & 0.05 & 0.11 & 0.06 & 0.09 & 0.09 \\
\hline & $F(d f)$ for change in $R^{2}$ & $\begin{array}{c}1.65 \\
(8,95)\end{array}$ & $\begin{array}{c}0.87 \\
(1,94)\end{array}$ & $\begin{array}{r}* * 4.53 \\
(2,92)\end{array}$ & $\begin{array}{c}* 2.26 \\
(8,163)\end{array}$ & $\begin{array}{l}* * 6.50 \\
(1,162)\end{array}$ & $\begin{array}{c}1.42 \\
(2,160)\end{array}$ \\
\hline
\end{tabular}

${ }^{\mathrm{a}}$ compared to university/college graduates; ${ }^{\mathrm{b}}$ compared to adequate income; ${ }^{\mathrm{c}}$ compared to fair to both $* p \leq 0.05 * * p \leq 0.01$

\section{DISCUSSION}

Epidemiological studies have only recently begun to investigate the potential consequences of family work for women's and men's mental health. The limited research which has examined the relationship between household work and well-being has produced equivocal findings, likely due in part to widely varying sample characteristics and a lack of specificity in the measurement of family work. We add to this limited but growing body of research by focusing our investigation specifically on parents with preschool children living in dual-earner households and by attempting a more fine-grained approach to our measurement of unpaid family work. The main finding of this study is that the division of unpaid family work is associated with parents' psychological well-being and that the nature of the association depends on both gender and the specific aspects of family work considered.

Our first research question focused on whether the division of child rearing and the division of housework were differentially associated with psychological distress. For fathers, neither the relative share of housework performed nor the relative share of child rearing performed were significantly related to psychological distress. Our findings are consistent with the results of previous research which has 
Table 6. OLS Regression of Psychological Distress on Relative Time in Primary Child Rearing and Secondary Child Rearing, by Gender

\begin{tabular}{|c|c|c|c|c|c|c|}
\hline & \multicolumn{3}{|c|}{ Men } & \multicolumn{3}{|c|}{ Women } \\
\hline Perceived relative time in secondary child rearing & .03 & .04 & .07 & .02 & .03 & .06 \\
\hline
\end{tabular}

a adjusted for age, number of children, educational attainment, perceived income adequacy, weekly work hours, job demands, job decision latitude $* \mathrm{p} \leq 0.05$

also failed to find a relationship between men's psychological well-being and their participation in housework $[8,16,21]$ or child rearing $[8,16]$.

For mothers in our study, the relationship between the division of housework, the division of child rearing, and psychological distress was more complex. We found that mothers' relative time spent in housework was unrelated to their psychological distress - at least when the division of housework was measured in aggregate form (see research question 2 below). On the other hand, the more time mothers spent in child rearing relative to their partner, the greater their psychological distress. Previous research which has considered child rearing and housework separately in relation to women's mental health have produced some equivocal findings $[8,16]$, though studies which have focused specifically on mothers of young children have produced results generally consistent with our study [20, 22, 36]. For example, Des Rivieres-Pigeon et al. [22] compared the sharing of family work and psychological distress in mothers one year following childbirth in Canada, France and Italy. These researchers found that in all three countries, women who reported always doing more than half of the various child rearing activities compared to a partner experienced greater psychological distress than women reporting less involvement. On the other hand, and similar to the results of our study, they found no association between the overall division of housework activities and psychological distress. Kessler and McRae [36] also reported that among working mothers with pre-school children, assistance from partners with child care but not housework influenced mothers' psychological distress. This body of research, combined with the results of our study, suggests that partners' assistance in child rearing may play a particularly critical role in mothers' mental well-being when young children are present in the household.

But why wasn't the psychological well-being of fathers in our study associated with the division of child rearing in a way similar to mothers? Gender differences in the activities associated with parenting may provide part of the answer. Research suggests that the time parents spend on particular child rearing activities is highly gendered, with mothers generally performing more of the physically and emotionally demanding tasks than fathers [7, 27]. To explore more closely the relationship between gender and child rearing activities among participants in our study, we cross-tabulated each item of our division of child rearing variable by gender (data not shown). We found that a significantly higher percentage of mothers than fathers reported taking care of their children's personal/medical care and helping/teaching them, "most or all of the time". Fathers reported more frequent involvement than mothers in reading/talking to their children and no statistically significant gender differences emerged for playing or children's travel arrangements We then examined whether particular aspects of child rearing were differentially associated with psychological distress by creating two new child rearing variables, one measuring perceived time spent in primary child rearing activities (ie., personal/medical care, helping/teaching) and the second focused on more secondary types of activities (ie., playing, reading/talking, travel). Results of the linear regression, shown in Table 6, indicated that more proportionate time spent in primary but not secondary child rearing activities was associated with greater psychological distress for mothers. For fathers, however, neither primary nor secondary child rearing activities were associated with psychological distress.

As mentioned, we found no statistically significant association between relative time spent in housework and psychological distress for either mothers or fathers. To answer our second research question, we disaggregated the housework variable further, examining whether the division of low-schedule-control housework tasks and high-schedulecontrol housework tasks were differentially associated with psychological distress. For fathers in our study, no statistically significant association emerged between psychological distress and perceived relative time spent in high- or lowschedule- control housework tasks. For mothers, however, greater perceived time spent in high-schedule-control housework tasks relative to one's partner (but not in lowschedule-control tasks) was associated with increased psychological distress. These findings are inconsistent with previous (albeit limited) research, which has identified the performance of low-schedule-control housework tasks as associated with lower mental well-being $[8,21]$ and the job stress literature, which has highlighted the harmful health effects of low job control [30].

What might account for our discrepant findings? The answer may partly lie in the adequacy of our measure of schedule-control. An important assumption in quantitative research is that the measures used are closely linked to the constructs they are intended to represent [37]. In the job stress literature, it is the perception of control over work scheduling, typically measured by multiple items on a likert scale, that appears protective for mental health [31,38,39]. In our study, we are assuming that the more proportionate time an individual spends in particular tasks, such as yard work or car maintenance, translates into a greater sense of control for that individual in how and when tasks are performed. However, the increased psychological distress associated with performing more of the high-schedule control tasks among 
women in our study, may have less to do with schedule control and more to do with demand overload; that is, perhaps for employed women with preschool children, performing more of the traditionally masculine tasks within the household, in addition to child rearing and other types of housework, only serves to add more stress to their already exceedingly busy lives. Although control in family work has been increasingly touted in the literature as a potentially important determinant of women's health $[40,41]$, the current lack of theoretical clarity is a major impediment to the development of appropriate measures. Additional research is clearly needed to elucidate which particular aspects of control in unpaid family work, including schedule control, are most important for well-being.

Our third question focused on evaluations of fairness; that is, whether perceived fairness in the division of housework (child rearing) was more strongly associated with psychological distress than the division of housework (child rearing). For mothers, the answer was a resounding "no": neither perceived fairness in the division of child rearing nor perceived fairness in the division of housework was related to psychological distress. Rather, as demonstrated above, the actual division of child rearing, particularly primary child rearing tasks, was more strongly associated with mothers' psychological distress, as was performing a higher proportion of high-schedule-control household tasks. This lack of association is surprising, given the results of previous research linking women's increased psychological distress with perceived unfairness in housework $[8,10,12,16]$ and child rearing [16]. Thus, although a substantial proportion of mothers in our study perceived the current division of housework $(29 \%)$ or child rearing $(24 \%)$ as unfair to themselves, this perception of unfairness did not translate into greater psychological distress.

In contrast to mothers, however, psychological distress for fathers was associated more strongly with perceptions of equity than with the actual division of family work. That is, compared to fathers who perceived the division of housework or child rearing as fair to both partners, those who perceived the division as unfair to themselves reported significantly higher levels of psychological distress. These findings, though consistent with equity theory [42] are inconsistent with the few previous studies which exists on the topic, which have reported no significant association between men's perception of inequity in housework $[8,12,16]$ or child rearing [16] and psychological distress. Differences in results between our study and previous research could be due, in part, to the nature of the samples studied. Compared to our study, participants in previous research on the topic have been older, with adolescent children, and varied employment statuses. Although additional research is needed to determine whether this finding can be replicated, the results of this study clearly suggest that, at least for relatively young fathers with preschool children in dual-earner households, a fairly strong association exists between perceptions of inequity in family work and their psychological well-being.

\section{LIMITATIONS OF THE STUDY}

Our study is cross-sectional, and therefore, we did not have enough evidence to establish the temporal relationship between psychological distress and family work; it is possi- ble, for example, that psychological distress actually preceded an unequal division of child rearing among mothers and/or perceived unfairness in family work among fathers.

The low response rate in the study also creates a strong potential for selection bias. Although comparisons conducted between our study sample and the CCHS 3.1 sample suggested considerable similarity, differences were also noted. However, the intent of our study was to examine associations between variables, rather than to estimate the prevalence of a particular health outcome/exposure. Some indication against the presence of bias is suggested by the fact that our analyses reproduced several factors that have already been more or less established as being related to psychological distress in previous research, such as income adequacy, job demands and workplace decision latitude $[43,44]$. On the other hand, given the low response rate, the presence of biased measures of effect cannot be ruled out; that is, we cannot rule out the possibility that the parents who agreed to participate may have differed from nonparticipants in their perceptions of the division of family work, their self reported experience of psychological distress, and the nature of the relationship between the two. In addition, given that the sample was comprised of participants from one specific geographical region in Canada, caution should be exercised in generalizing the results to a broader population of employed parents with young children.

Limitations in measurement are also present. All of our measures were self-reported. Previous research suggests that both men and women tend to overestimate their own contributions to family work in direct-question surveys $[45,46]$. Another limitation is the use of proportionate measures to calculate the division of household labor, which do not provide information on how much time is exactly spent on each household task. In addition, although we were interested in the division of family work in dual-earner households, we surveyed individuals rather than couples. It is also important to note that the amount of variance explained by our regression models was fairly small. Thus, additional factors need to be considered as potential sources of psychological distress for mothers and fathers. In our study, we did not include emotional work (e.g., conflict mediation, providing comfort and encouragement to partner and children) in the division of household tasks, nor other types of family work, such as coordinating family activities, volunteering, and coaching teams.

\section{IMPLICATIONS FOR FUTURE RESEARCH}

Understanding of the relationship between unpaid family work and mental health is rudimentary at present. Longitudinal research with couples is clearly needed to tease out the temporal relationship between the division of family work and the development of psychological distress. More research with diverse samples of participants, in terms of life stage, family composition, sexual orientation, marital status, ethnicity, and socioeconomic position, is also required.

Valid and reliable exposure assessment is a challenge in almost every observational study, but particularly in a relatively new field of inquiry such as this. Clearly articulated theory is critical for the development of valid and reliable measures. As observed by several researchers [4] "research 
on work within the home is still in its infancy. We do not have conceptual frameworks which are as well developed as in the case of paid work, nor are the elements of domestic labor clearly identified" (p.679). To advance the field, conceptual models need to be developed and used to inform the development of measures that more fully capture the complexity of family work, including concepts such as schedule control and fairness. Toward this end, qualitative research with couples would be particularly useful as a means of deepening our understanding of the nature of family work, the meaning mothers and fathers attach to housework and child rearing, and how they negotiate the sharing of such work within the family.

\section{CONCLUSION}

Family work is complex and its study poses a number of conceptual and methodological challenges. Although study limitations temper any firm conclusions, the results of this study, combined with previous research, suggest that the gendered nature of household work has implications for the psychological well-being of both mothers and fathers of preschool children in dual-earner households. However, more longitudinal research, combined with the use of theoretically-informed measures of family work and a higher response rate, is needed to advance the field.

\section{ACKNOWLEDGEMENT}

This research was funded by the Canadian Institutes of Health Research, Grant\# 67129 awarded to BLJ.

\section{REFERENCES}

[1] Klumb P, Lampert T. Women, work, and well-being 1950-2000: a review and methodological critique. Soc Sci Med 2004; 58: 100724.

[2] Artazcoz L, Borrell C, Cortas I, Escriba-Aguir V, Cascant L. Occupational epidemiology and work related inequalities in health: a gender perspective for two complementary approaches to work and health research. J Epidemiol Commun Health 2007; 61: 39-45.

[3] Messing K, Stellman J. Sex, gender and women's occupational health: the importance of considering mechanism. Environ Res 2006; 101: 149-62.

[4] Walters V, McDonough P, Strohschein L. The influence of work, household structure, and social, personal and material resources on gender differences in health: an analysis of the 1994 Canadian National Population Health Survey. Soc Sci Med 2002; 54(5): 677-92.

[5] Coltrane S. Research on household labor: modeling and measuring the social embeddedness of routine family work. J Marriage Fam 2000; 62(4): 1208-33.

[6] Marshall K. The family work week. Perspect Labor Income 2009; 10(4): 5-13.

[7] Marshall K. Converging gender roles. Perspect Labor Income 2006; 7(7): 5-17.

[8] Robinson J, Spitze G. Whistle while you work? The effect of household task performance on women's and men's well-being. Soc Sci Quar 1992; 73(4): 845-61.

[9] Goode, WJ. A theory of role strain. A Soc Rev 1960; 25(4): 48396.

[10] Lennon M, Rosenfield S. Relative fairness and the division of housework: the importance of options. Am J Soc 1994; 100(2): 506-31.

[11] Thompson L. Family work: women's sense of equity and of fairness. J Fam Issues 1991; 12: 181-96.

[12] Glass J, Fujimoto T. Housework, paid work, and depression among husbands and wives. J Health Soc Behav 1994; 35(2): 179-91.

[13] Borrell C, Muntaner C, Benach J, Artazcoz L. Social class and selfreported health status among men and women: what is the role of work organization, household material standards and household labor. Soc Sci Med 2004; 58(10): 1869-87.
[14] Bird CE, Freemont A. Gender, time use, and health. J Health Soc Behav 1991; 32: 114-29.

[15] Bird CE. Gender, household labor, and psychological distress: the impact of the amount and division of housework. J Health Soc Behav 1999; 40(1): 32-45.

[16] Voydanoff P, Donnelly B. The intersection of time in activities and perceived unfairness in relation to psychological distress and marital quality. J Marriage Fam 1999; 61(3): 739-51.

[17] Escriba-Aguir V, Tenias-Burillo J. Psychological well-being among hospital personal: the role of family demands and psychosocial work environment. Int Arch Occup Environ Health 2004; 77: 401-8.

[18] Khawaja M, Habib R. Husbands' involvement in housework and women's psychosocial health: findings from a population-based study in Lebanon. Aust J Polit Hist 2007; 97(5): 860-6.

[19] Goldberg AE, Perry-Jenkins M. Division of labor and workingclass women's well-being across the transition to parenthood. J Fam Psychol 2004; 18(1): 225-36.

[20] Matthews S, Power C. Socio-economic gradients in psychological distress: a focus on women, social roles and work-home characteristics. Soc Sci Med 2002; 54: 799-810.

[21] Barnett R, Shen Y. Gender, high- and low-schedule-control housework tasks, and psychological distress: a study of dual-earner couples. J Fam Issues 1997; 18(4): 403-28.

[22] Des Rivieres-Pigeon C, Saurel-Cubizolles MJ, Romito P. Division of domestic work and psychological distress 1 year after childbirth: a comparison between France, Quebec and Italy. J Commun Appl Soc Psychol 2002; 12: 397-409.

[23] Moen P, Yu Y. Effective work/life strategies: working couples, work conditions, gender and life quality. Soc Probl 2000; 47(3): 291-326.

[24] Gjerdingen DK, Center B. First-time parents' postpartum changes in employment, childcare, and housework responsibilities. Soc Sci Res 2005; 34: 103-16.

[25] Baxter J, Hewitt B, Haynes M. Life course transitions and housework: marriage, parenthood and time on housework. J Marriage Fam 2008; 70: 259-72.

[26] Beaujot R, Liu J. Models of time use in paid and unpaid work. J Fam Issues 2005; 26(7): 924-46.

[27] Craig L. Does father care mean fathers share? A comparison of how mothers and fathers in intact families spend time with children? Gend Soc 2006; 20(2): 259-81.

[28] Sayer L. Gender, time and inequality: Trends in women's and men's paid work, unpaid work and free time. Soc Forces 2005; 84(1): 285-303.

[29] Ross C, Mirowsky J, Huber J. Dividing work, sharing work, and inbetween: marriage patterns and depression. Am Soc Rev 1983; 48(6): 809-23.

[30] Karasek R, Brisson C, Kawakami N, Houtman I, Bongers P, Amick B. The Job Content Questionnaire: an instrument for internationally comparative assessments of psychosocial job characteristics. J Occup Health Psychol 1998; 3: 322-55.

[31] Ala-Mursula L, Vahtera J, Linna A, Pentti J, Kivimaki M. Employee worktime control moderates the effects of job strain and effort-reward imbalance on sickness absence: the 10-town study. J Epidemiol Commun Health 2005; 59: 851-7.

[32] Statistics Canada. Canadian Community Health Survey, Cycle 3.1 (2005). Public use microdata file documentation. Ottawa, Ontario: author 2006.

[33] Kessler R, Andrews G, Colpe L, et al. Short screening scales to monitor population prevalences and trends in nonspecific distress. Psychol Med 2002; 32: 959-76.

[34] Kessler R, Barker P, Colpe J, et al. Screening for serious mental illness in the general population. Arch Gen Psychiatr 2003; 60: 184-189.

[35] Furukawa TA, Kessler RC, Slade T, Andrews G. The performance of the K6 and K10 screening scales for psychological distress in the Australian National Survey of Mental Health and Well-Being. Psychol Med 2003; 33: 357-62.

[36] Kessler R, McRae J, James A. The effect of wives' employment on the mental health of married men and women. Am Soc Rev 1982; 47(2): 216-27.

[37] DeVillis R. Scale development: theory and applications. Newbury Park: Sage 2003. 
[38] Thomas L, Ganster D. Impact of family-supportive work variables on work-family conflict and strain: a control perspective. J Appl Psychol 1995; 80(1): 6-15.

[39] Moen P, Kelly E, Huang Q. Work, family and life-course fit: does control over work time matter? J Vocat Behav 2008; 73: 414-25.

[40] Griffin J, Fuhrer R, Stansfeld S, Marmot M. The importance of low control at work and home on depression and anxiety: do these effects vary by gender and social class? Soc Sci Med 2002; 54(5): 783-98.

[41] Chandola T, Kuper H, Singh-Manoux A, Bartley M, Marmot M. The effect of control at home on CHD events in the Whitehall II study: gender differences in psychosocial domestic pathways to social inequalities in CHD. Soc Sci Med 2004; 58: 1501-9.
[42] Bartely S, Blanton P, Gilliard J. Husbands and wives in dual-earner marriages: decision-making, gender role attitudes, division of household labor, and equity. Mar Fam Rev 2005; 37: 69-94.

[43] Orpana H, Lemyre L, Gravel R. Income and psychological distress: the role of the social environment. Health Rep 2009; 20(1): 1-8.

[44] Stansfeld S, Candy B. Psychosocial work environment and mental health - A meta-analytic review. Scand J Work Environ Health 2006; 32(6): 443-62.

[45] Bonke J. Paid work and unpaid work: diary information versus questionnaire information. Soc Indicat Res 2005; 70: 349-68.

[46] Kamo Y. "He said, she said": Assessing discrepancies in husbands and wives' reports of the division of household labor. Soc Sci Res 2000; $29: 459-76$.

Received: August 05, 2009

(C) Tao et al.; Licensee Bentham Open.

This is an open access article licensed under the terms of the Creative Commons Attribution Non-Commercial License (http://creativecommons.org/licenses/by-nc/3.0/) which permits unrestricted, non-commercial use, distribution and reproduction in any medium, provided the work is properly cited. 